Ethiopian Journal of Environmental Studies \& Management 9(3): 278 - 286, 2016.

ISSN:1998-0507

doi: http://dx.doi.org/10.4314/ejesm.v9i3.3

Submitted: November 04, 2015

Accepted: April 27, 2016

\title{
ANALYSIS OF RESIDENTS' LOCATIONAL PREFERENCES IN THE PERI-URBAN RESIDENTIAL NEIGHBOURHOODS OF MINNA, NIGERIA
}

\author{
*POPOOLA, N.I.,1 JINADU, A.M. ${ }^{2}$ AND DALIL, M. ${ }^{2}$ \\ ${ }^{1}$ Department of Estate Management and Valuation, School of Environmental Technology, \\ Federal University of Technology Minna, Nigeria \\ ${ }^{2}$ Department of Urban and Regional Planning, School of Environmental Technology, \\ Federal University of Technology Minna, Nigeria
}

\begin{abstract}
Households make decision on their residential location after sorting out all issues relating to their demographic characteristics. This study therefore aimed at assessing the core and auxiliary factors influencing residents' choice of peri-urban residential neighbourhoods of Minna in Niger State, Nigeria. Six peri-urban neighbourhoods were selected for the study from which 600 households were sampled. Results of analysis revealed that household's income, house rents, proximity to places of work and security are core factors influencing resident's decision in the choice of residential location while land rents, presence of infrastructure and ethnic/religious factors are auxiliary factors. Friedman's test revealed more favourable rankings of land value factor over the other six factors. However, results of analysis (chi-square $=25.43 ; d f=6 ; p=0.000$ is < 0.01), indicated that there was a differential rank ordered preference for the seven (7) factors across the selected neighbourhoods. Economic empowerment, investment in residential housing, infrastructure refurbishing and provision were recommended for the attainment of optimum satisfactions in individual household's choice of residential location and for the achievement of sustainable development in the peripherals.
\end{abstract}

Key Words: Peri-Urban, Residential, core and Auxiliary factors

\section{Introduction}

Household residential location choices are dependent on a wide range of housing and location attributes which reflects various household characteristics. This differentiation in choices identifies and characterizes the relative importance of different attributes to various types of household (Kim et al., 2003). Over the years, studies have been carried out on reasons why individuals chose to live in a particular location or district. Empirical studies revealed different reasons why residents prefer some residential districts to the others. For instance, Florez (2002) observed that residential location choice is not only a function of accessibility, but also, of a set of other factors, such as neighbourhood and dwelling attributes as well as household characteristics. The study sustained that household characteristics and restrictions (such as income) first defined their location expectations, followed by neighbourhood

*Corresponding Author: Popoola, N.I.

Email: naomi.popoola@yahoo.com 
and dwelling attributes (like accessibility, urban quality and social characteristics of the vicinity) which are evaluated in order to decide on the location. In a similar study, Kim et al. (2003) established that transport related attributes have significant impacts on residential location choice.

In a related study, Rivera and Tiglao (2005) used disaggregate modeling approach to investigate the spatial behavior and mode choice behavior of two-worker households. The study revealed travel time and travel cost play significant roles in household's choice of residential location as households are willing to tradeoff longer distances and commuting time in their residential location choices. They concluded that residential location choice of household involves trade-offs among several factors which give the household the highest possible utility. However, Isaac et al. (2006) reported that their study on household's location preference across central city and suburban school districts in Columbus, Ohio area in 1995 using a hybrid conditional logit choice model revealed natural migration of households to the city suburbs due to job location, residential filtering, household income and lifecycle, flight from blight- due to lower school quality, higher crime levels, and lower average income levels in the city. The study further revealed that school quality exerts the strongest influence amongst all other residence locational factors observed. Also, in a similar study carried out by Cho et al. (2008) in Mecklenburg County, Northern Carolina; it was observed that access to certain employment sub-centers, measured in terms of generalized cost, is an important determinant of households' residential location decisions.
Acheampong and Anokye (2013) conducted a study on residents' location preference in the peri-urban residential settlements of Abrepo and Esreso in Kumasi, Ghana. The study explored the factors that inform households' decisions to live in Kumasi's peri-urban settlements while also considering the likelihood of households' change of residence in the future, their stated residential location preferences and the implications these decisions would have on sustainable urban growth. The findings revealed that family relations, relatively low land price and house rents as well as work-place proximity were the most significant factors influencing households' choice of the peri-urban areas. They concluded that the urban fringe will continue to experience an increase in residential housing development due to the advantages of aggregate cost reductions and called for the formulation of developmental policies for the urban fringe to ensure sustainable development.

Related researches such as the works of Sanni and Akinyemi (2009) on Ibadan were also carried out in Nigeria. The authors observed that individuals and families sort out the districts that best suit their social and/or economic class. That is, different category of residential density district of the city has distinct set of household's residential districts preferences peculiar to it. Similar study was conducted on residential districts within $5 \mathrm{~km}$ radius of the Kaduna South industrial hub in Kaduna, Nigeria by Akinbamijo (2012). The study revealed that majority of the residents within the study area fall within the deprived low income group and was attracted to their present locations by low rents and proximity to place of work, not minding 
the poor housing and environmental conditions of the area. Related study on Minna by Popoola and Aliyu (2010) revealed that easy accessibility to houses and other opportunities are of high priorities in the choice of residential locations within the study area.

It is evidenced from empirical the above studies that individual household will locate in the area that has a relatively comparative advantage over all other locations depending on their individual demographic and socio-economic status. These and other studies have generally considered important or most significant residential location factors. However, much has not been done in the isolation of the core and auxiliary variables of residential location, most especially in Minna. This study therefore seeks to assess the core and auxiliary factors influencing residents' choice of periurban residential neighbourhoods of Minna. The outcomes of the study will help urban planners, households and investors in real estate decision making and sustainable development planning in the peripheral areas of Minna.

\section{Statement of Problems}

The increases in population at the urban fringe are mostly associated with rapid urban growth due to high rates of migration to urban areas. Minna has grown and developed into a modern city since its creation as the state capital in 1976. The modernization is however not without the attendant problems such as; increase in residents' mobility from city core to the fringe, clustered low quality dwellings on an unplanned vast area of land, lack of community facilities and basic services, proliferations of sprawling and slum settlements, increase in land and rental value. The emerging scenario has implications for good quality of life and wellbeing of the residents. It is therefore important to identify the factors at play for the purpose of managing the consequences.

\section{Study Area}

Minna, the capital of Niger State is located between Longitude $3^{\circ} 30^{\prime} \mathrm{E}$ and $7^{\circ} 20^{\prime} \quad \mathrm{N}$ and Latitudes $8^{\circ} 20^{\prime} \mathrm{N}$ and $11^{\circ} 30^{\prime} \mathrm{N}$ (figure 2). Minna is about $135 \mathrm{~km}$ away from the Federal Capital Territory and $300 \mathrm{~km}$ away from Kaduna city. Within Niger State, it is about $90 \mathrm{~km}$ away from Bida, $100 \mathrm{~km}$ away from Suleja and about 130km from Kotangora. The town lies on a relatively high land with a site height of between $240 \mathrm{~m}-270 \mathrm{~m}$ above sea level. It is surrounded by a range of hills that stretch from north east westward towards Bosso and Tudun Fulani (Sanusi, 2006). The town is dissected at the lower part by River Suka and its tributaries. In the Southeast part of the town lays River Chanchaga which has been dammed to provide water for the greater part of the town. The division of Minna based on neighbourhoods shows that Minna has twenty-five (25) neighbourhoods. 


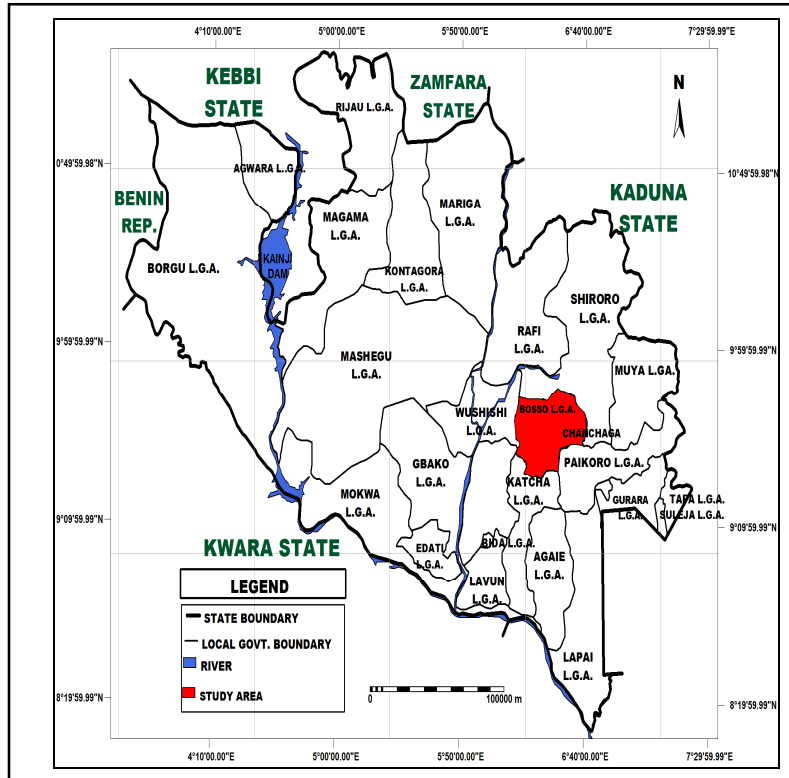

Figure.1.:Location of Niger State in Nigeria

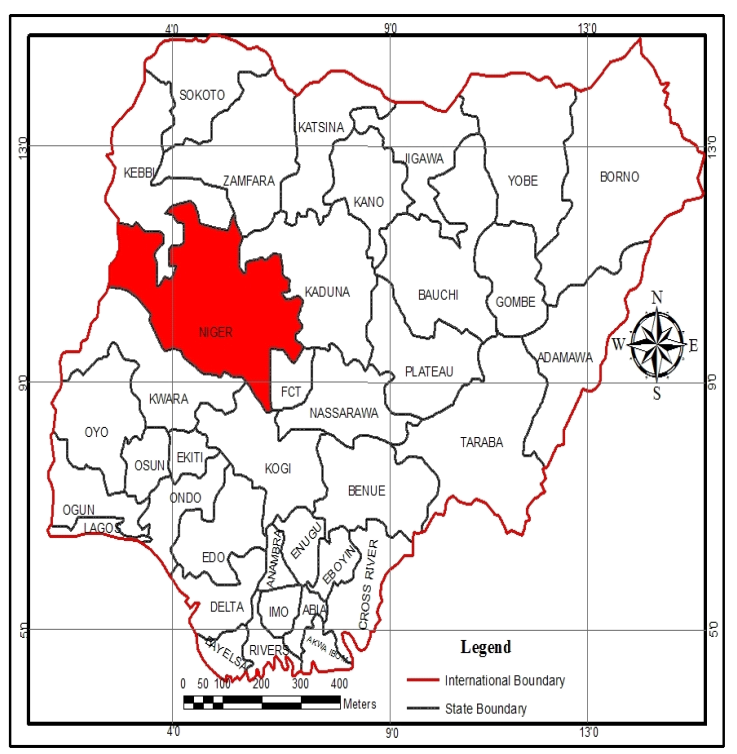

Figure.2: Location of Minna in Niger State.

Source: Federal Ministry of Lands, Housing and Urban Development, Abuja.(2013); Ministry of Lands and Housing, Minna.(2013).

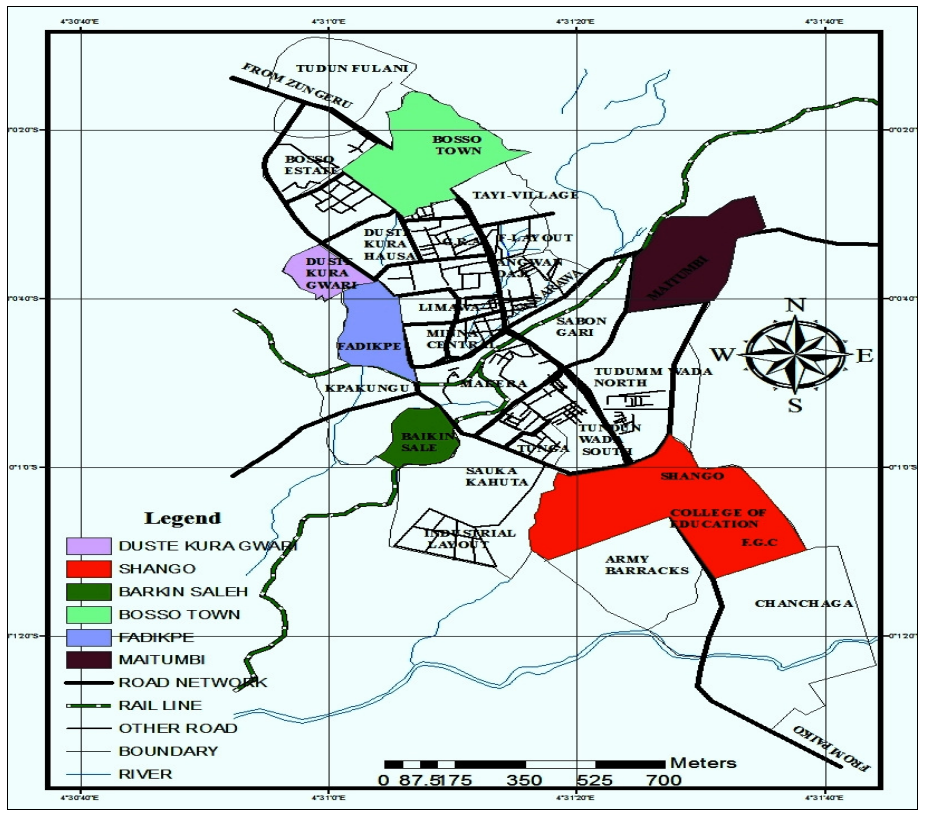

Figure 3. Delineated Boundaries of Sampled Neighbourhoods. Source: Adapted from Minna Street Map, 2014 
Methodology

Selection of Sampled Neighbourhoods

Cluster sampling technique was adopted in the section of sample areas for the study. In a previous research by Baba and Jinadu (2001); two peripheral residential zones were identified in Minna, namely; South-West peripheral and North-West peripheral zones. However for the purpose of this study, the peripheral residential neighbourhoods were zoned into three namely; SouthWest peripheral, North-West peripheral and North-East peripheral zones with each zone representing a cluster. Two neighbourhoods were randomly selected within each cluster (zone) to ensure equal representation from each zone. The selected neighbourhoods formed the sample areas for this study. From the South-Western zone emerged BarkinSale and Shango while Fadikpe and Dutsen-kura (Gwari) were selected the North-Western zone and the NorthEastern zone has Bosso and Maitumbi (figure 3).

\section{Sample Frame and Sample Size}

Total number of household in all the six neighbourhoods under study is 18,387 while a sample size of 600 was derived using Adams et al. (2007) simplified formula $\left(\mathrm{n}_{0}=\mathrm{Z}^{2} \alpha / 2 \times \mathrm{P}(1-\mathrm{P}) / \mathrm{d}^{2}\right)$. A $95 \%$ confidence level, estimate rate of $50 \%$ $(\mathrm{p}=.50)$ and precision range of $4 \%$ $(\mathrm{d}=0.04)$ were adopted for the study. The sample size was distributed proportionally amongst selected neighbourhoods while systematic random sampling technique was adopted in the administration of questionnaires; questionnaires were administered on every three house chosen on every identified street from which a household is chosen.

\section{Analysis of Residents' Locational Preference Factors}

Microsoft Excel was employed in analysing factors influencing resident's locational preference in each neighbourhood under study. The variables used in this study were derived from the result of preliminary study carried out across the selected neighbourhoods between in August, 2014. Seven (7) variables were sorted from preliminary findings as possible factors influencing residential locational preference amongst the residents of the selected neighbourhoods. The variables identified and used in the analysis are; ethnic/religious factors, low land value, low housing rent, disposable income, proximity to place of work, presence of infrastructure and secured environment. Core and auxiliary factors influencing locational preference were established using Likert Scale and weight ranging from 5 to 1 . That is, very significant (5); significant (4); undecided (3); not significant (2) and not very significant (1). Mean score and relative index were calculated for each influencing factor to assess the ranking of factors. Standard deviation was also calculated to assess the rate of convergence and divergence of residents' responses. SPSS was used to conduct a Friedman test for the ranking of responses across selected neighbourhoods.

\section{Results and Discussion}

\section{Locational Preference Factors Influencing Spatial Growth in the Peri- Urban}

Empirical studies revealed that factors influencing resident's choices of location range from housing location to physical attributes of the environment, socio-economic attributes, housing and 
neighbourhood attributes (Florez, 2002; Kim et al, 2003; Sanni and Akinyemi, 2009). Analysis of locational preference factors influencing spatial growth in the peri-urban revealed that low rental values obtainable in the neighbourhoods attracted the increasing population coming into the city to the peri-urban. $72.93 \%$ of respondents attested to the fact that low rents attracted them to the neighbourhood. Closely related to this factor is the resident's level of disposable income as $66.42 \%$ of respondents maintained that they found housing accommodation within the level of their disposable income in the peri-urban. $62.54 \%$ of residents affirmed that proximity to places of work is part of reasons why they chose their present housing location while $54.41 \%$ maintained that secured environment where safety of lives and property are guaranteed attracted them the peri-urban. The aforementioned factors are core locational factors that influenced the spatial growth of Minna peri-urban.

The auxiliary factors influencing spatial growth are ethnic/religious factors, presence of infrastructure and low land value. 35.89\%, 30.03\% and $29.77 \%$ of the respondents respectively attested to the significance of these factors in the choice of their in their choice of present location. The low ranking of land value factor and high ranking of rental factor raises question on the rates of homeownership amongst the peri-urban residents (Table 1).

Table 1: Aggregate Resident's Locational Preference Factors Peri-urban neighbourhoods of Minna

\begin{tabular}{|c|c|c|c|c|c|c|c|c|c|c|}
\hline \multirow[t]{2}{*}{$\mathrm{S} / \mathrm{N}$} & \multirow[t]{2}{*}{ Influencing factors } & \multicolumn{5}{|c|}{ Valid Responses } & \multirow{2}{*}{$\begin{array}{c}\text { Valid } \\
\text { Case } \\
(\mathrm{N}=600)\end{array}$} & \multirow{2}{*}{$\begin{array}{c}\text { Mean } \\
\text { Score }^{a}\end{array}$} & \multirow{2}{*}{$\begin{array}{c}\text { Ran } \\
k\end{array}$} & \multirow[t]{2}{*}{$\mathrm{C} / \mathrm{A}^{\mathrm{b}}$} \\
\hline & & VS & $\mathrm{S}$ & UD & NVS & NS & & & & \\
\hline 1 & Ethnic/religious factors & 10.89 & 25.00 & 20.00 & 16.96 & 27.14 & 560 & 2.76 & 5 & A \\
\hline 2 & Low land value & 7.94 & 21.83 & 30.36 & 17.06 & 22.82 & 504 & 2.75 & 6 & A \\
\hline 3 & Low housing rent & 17.51 & 55.42 & 7.94 & 10.65 & 8.48 & 554 & 3.63 & 1 & $\mathrm{C}$ \\
\hline 4 & Disposable income & 14.96 & 51.46 & 12.59 & 12.59 & 8.39 & 548 & 3.52 & 2 & $\mathrm{C}$ \\
\hline 5 & Proximity to place of work & 20.18 & 42.36 & 12.91 & 14.91 & 9.64 & 550 & 3.49 & 3 & $\mathrm{C}$ \\
\hline 6 & Presence of infrastructure & 4.76 & 25.27 & 16.85 & 29.49 & 23.63 & 546 & 2.58 & 7 & A \\
\hline 7 & Secured environment & 9.55 & 44.86 & 14.05 & 17.30 & 14.23 & 555 & 3.18 & 4 & $\mathrm{C}$ \\
\hline & Average & 12.26 & 38.03 & 16.50 & 16.39 & 16.99 & & 3.13 & & \\
\hline
\end{tabular}

${ }^{a}$ mean score is derived by assigning values to the valid response in order of importance: very significant (VS)=5; Significant (S)=4; Undecided(UD)=3; Not Very Significant(NVS)=2; Not Very Significant(NVS)=2; Not Significant(NS)=1

${ }^{\mathrm{b}}$ The influencing factors are grouped either as Auxiliary(A) or Core(C) factors

\section{Analysis of Differences in Mean Responses on Locational Preferences Factors}

Mean responses for the seven (7) locational preferences influencing factors was compared across the selected neighbourhoods to observe differences in mean responses. The study observed close convergence in mean responses of six factors (factors 1, 2,3,4,5 and 7); except for factor 6 where means scores ranged from 2.45 to 3.43 (Table 2). 
Table 2: Mean Response of Residents on Locational Preference Factors in Minna Periurban

\begin{tabular}{llccccccc}
\hline SN & Neighbourhood & Factor & Factor & Factor 3 & Factor 4 & Factor 5 & Factor 6 & Factor 7 \\
& & 1 & 2 & & & & & \\
\hline 1 & Dutsen-kura(Gwari) & 2.56 & 2.60 & 3.10 & 3.33 & 3.16 & 2.83 & 3.00 \\
2 & Fadikpe & 2.77 & 2.93 & 3.33 & 3.31 & 3.53 & 3.43 & 3.83 \\
3 & Barkin-sale & 2.15 & 2.32 & 3.51 & 3.63 & 3.20 & 2.46 & 3.22 \\
4 & Shango & 2.74 & 2.46 & 3.98 & 3.46 & 3.81 & 2.62 & 3.29 \\
5 & Bosso & 2.92 & 2.74 & 3.68 & 3.48 & 3.55 & 2.52 & 3.18 \\
6 & Maitumbi & 2.62 & 2.55 & 3.67 & 3.72 & 3.47 & 2.45 & 3.05 \\
\hline
\end{tabular}

*Factors: 1..Ethnic/religious factors; 2. Low land value; 3. Low housing rent; 4. Disposable income; 5. Proximity to place of work; 6. Presence of infrastructure; 7. Secured environment.

A Friedman test was conducted to determine whether respondents had a differential rank ordered preference for the seven location influencing factors in Minna peri-urban. Results of the analysis revealed that low land value has the lowest mean value of 2.6 and standard deviation of 0.21 . This implies closeness in the ranking of the factor across the neighbourhood. Ethnic and religious factors rated second in ranking in of responses. Even though level of income ranked sixth in the mean ranking, there seems to be more convergence in opinion of respondents $(\mathrm{std}=0.16)$ as regard this factor (Table 3).

Table 3: Descriptive Statistics for Friedman's Test

\begin{tabular}{llccccc}
\hline S/N & Influencing factors & $\mathrm{N}$ & Mean & Std. Deviation & Minimum & Maximum \\
\hline 1 & Ethnic/Religious & 6 & 2.6267 & .26500 & 2.15 & 2.92 \\
2 & Low land value & 6 & 2.6000 & .21401 & 2.32 & 2.93 \\
3 & Low housing rent & 6 & 3.5450 & .30612 & 3.10 & 3.98 \\
4 & Disposable income & 6 & 3.4883 & .16216 & 3.31 & 3.72 \\
5 & Proximity to place of work & 6 & 3.4533 & .24205 & 3.16 & 3.81 \\
6 & Presence of infrastructure & 6 & 2.7183 & .37595 & 2.45 & 3.43 \\
7 & Secured environment & 6 & 3.2617 & .29849 & 3.00 & 3.83 \\
\hline
\end{tabular}

The Friedman chi-square tests the null hypothesis that, the ranks of the factors do not differ from their expected value. Therefore the null and alternate hypotheses for this test are stated thus; $\mathbf{H}_{\mathbf{0}}=$ There is no statistically significant difference in true mean ranking of locational preference factors across the six selected peri-urban residential neighbourhoods in Minna.

$\mathbf{H}_{\mathbf{1}}=$ There is statistically significant difference in true mean ranking of locational preference factors across the six selected peri-urban residential neighbourhoods in Minna.

Result of the Friedman's test on mean responses ranking revealed that low land value ranked higher than the other six (6) locational preference factors are shown in Table 4. This implies that there is similarity in the mean ranking for low land value across the selected neighbourhoods. Low land value ranked $6^{\text {th }}$ in the order of preference in five of the sampled neighbourhoods; except for Shango where it ranked as the $7^{\text {th }}$ factor. 
Table 4: Friedman's Result of Similarity in Mean Ranking of Factors

\begin{tabular}{llc}
\hline SN & Influencing Factors & Mean Rank \\
\hline 1 & Ethnic/Religious & 2.00 \\
2 & Low land value & 1.83 \\
3 & Low housing rent & 5.83 \\
4 & Disposable income & 5.67 \\
5 & Proximity to place of & 5.50 \\
& work & 2.50 \\
6 & Presence of & \\
& infrastructure & 4.67 \\
7 & Secured environment & \\
\hline
\end{tabular}

Even though there were significantly more favorable rankings of Land value factor over the other six factors, the result of analysis (chi-square $=25.43 ; \mathrm{df}=6$; $\mathrm{p}=0.000$ is $<0.01$ ), indicated that there was a differential rank ordered preference for the seven (7) factors across the selected neighbourhoods. The null hypothesis is therefore rejected and the alternate hypothesis which states that, there is significant difference in true mean ranking of locational preference factors across the six selected peri-urban residential neighbourhoods in Minna is accepted (Table 5).

Table 5: Friedman's Test Statistics

\begin{tabular}{ll}
\hline $\mathrm{N}$ & 6 \\
Chi-Square & 25.429 \\
df & 6
\end{tabular}

Asymp. Sig. $\quad .000$

\section{Findings and Implication}

Field investigations and data analysis identified natural increase in population and rural-urban/urban-urban migration, availability of large expanse of cultivated and uncultivated land within the neighbourhoods, increasing demands for developable lands and complexity of communal system of land ownership as likely factors influencing the spatial growth of Minna peri-urban neighbourhoods. Core locational factors influencing spatial growth in the neighbourhoods are, low rental values as $72.93 \%$ of respondents rated it as being significant in their choice of the periurban. Other core factors are level of resident's disposable income; proximity to places of work and secured environment which rated $66.42 \%$, $62.54 \%$ and $54.41 \%$ respectively on the significant scale.

The auxiliary factors influencing spatial growth in the neighbourhoods are ethnic/religious factors, presence of infrastructure and low land value. The low ranking of land value factor (29.77\%) amongst location influencing factors and high ranking of rental factor $(72.93 \%)$ raises question on the rates of homeownership amongst the peri-urban residents. These findings confirmed the results of Akinbamijo (2012) who observed that low rents and proximity to place of work are core factors influencing the choice of peri-urban areas; but however differ from initial findings of Popoola and Aliyu (2010) who found out that easy accessibility to houses and other opportunities are of high priorities in the choice of residential locations in Minna.

\section{Conclusion and Recommendations}

The results of the research show that several factors influence the locational references of the residents of the periurban areas of Minna. However, housing affordability as exemplified in low rental values, proximity to work place and relative security in the peri-urban areas are the major locational factors. These factors are capable of increasing the rate of peri-urban growth in the study area. Since the peri-urban areas are becoming the home for more residents, it is important to invest more in housing and infrastructure to cater for the growing population of peri-urban in Minna. It is therefore recommended that the municipal government and private 
investors should provide more infrastructure and refurbish the few existing ones. Also, the government, real estate developers and prospective investors should consider investment in peri-urban housing in order to cater for the growing demand in the neighbourhoods.

\section{References}

Adams, J., Hafiz, T.A.K., Raeside, R. and White, D. (2007). Research Methods for Graduate Business and Social Science Students. Response Books by SAGE Publications, B1/I1, Mohan Cooperative Industrial Area Mathura Road. New Delhi .

Acheampong, R.A. and Anokye, P.A. (2013). Understanding Households' Residential Location Choice in Kumasi's Peri-Urban Settlements and the Implications for Sustainable Urban Growth. Research on Humanities and Social Sciences, (3)9: 60-70.

Akinbamijo, O.B. (2012). Urban Environmental Justice and the Missing Links: A Study of High Density Residential Districts of Kaduna, Nigeria. The Built \& Human Environment Review, 5: 14-27.

Baba, J.M. and Jinadu, A.M. (2001). Analysis of Spatial Variations in the Occurrence of Housing EnvironmentRelated Diseases in Minna Metropolis. Minna: Federal University of Technology, Minna.

Cho, E.J., Rodriguez, D.A. and Song, Y. (2008). The role of employment subcenters in residential location decisions. Journal of Transport and Land Use, 1(2): 121-151.

Florez, J. (2002). Effects of Accessibility On Residential Land Patterns. Unpublished $\mathrm{PhD}$ thesis at Universidad Politrenica de Catalufia,
Departamento de Infraestructura del Transportey Territorio (Esp a). Support of COl,IICIT Venezuela.

Isaac, B.I., Irwin, E.G. and Haab, T. (2006). Determinants Of Residential Location Choice: How Important Are Local Public Goods In Attracting Homeowners To Central City Locations. Journal of Regional Science, 46(1), 97-120.

Kim, J., Pagliara, F. and Preston, J.M. (2003). An Analysis of Residential Location Choice Behaviour in Oxfordshire, UK: A Combined Stated Preference Approach. International Review of Public Administration, 8(1), 103 - 114.

Popoola, N.I. and Aliyu, J.S. (2010). Determinants of Tenant's Preference for Residential Property Location within Minna, Nigeria .Journal of Geography, Environment \& Planning, 6(2): 1-7.

Rivera, M.A.I. and Tiglao, N.C. (2005). Modeling Residential Location Choice, Work place Location Choice and Mode Choice of Two-Worker Households in Metro Manila, Proceedings of the Eastern Asia Society for Transportation Studies, 1167 - 1178.

Sanni, L. and Akinyemi, F.O. (2009). Determinants of Household's Residential Districts' Preferences within Metropolitan City of Ibadan, Nigeria. Journal of Human Ecology, 25(2): 137-141.

Sanusi, A.Y. (2006), The Assessment of the Spatial Relationship between poverty and Environmental Quality in Minna Metropolis Niger State Nigeria. Unpublished Ph.D project, Geography Department. Federal University of Technology, Minna, Niger state. 